\title{
Review Article \\ Brazilian Spotted Fever with an Approach in Veterinary Medicine and One Health Perspective
}

\author{
Sabrina Destri Emmerick Campos, ${ }^{1}$ Nathalie Costa da Cunha, ${ }^{2}$ \\ and Nádia Regina Pereira Almosny ${ }^{1}$ \\ ${ }^{1}$ Departamento de Patologia e Clínica Veterinária, Universidade Federal Fluminense, 24230-340 Niterói, RJ, Brazil \\ ${ }^{2}$ Departamento de Saúde Coletiva Veterinária e Saúde Pública, Universidade Federal Fluminense, 24230-340 Niterói, RJ, Brazil \\ Correspondence should be addressed to Sabrina Destri Emmerick Campos; s.destri@gmail.com
}

Received 29 September 2015; Revised 15 December 2015; Accepted 16 December 2015

Academic Editor: Francesca Mancianti

Copyright (C) 2016 Sabrina Destri Emmerick Campos et al. This is an open access article distributed under the Creative Commons Attribution License, which permits unrestricted use, distribution, and reproduction in any medium, provided the original work is properly cited.

\begin{abstract}
There is increasing interaction between man and pathogens transmitted by arthropods, especially by ticks. It is on this background that a holistic approach stands out, for the sake of Public Health. Brazilian Spotted Fever is an endemic disease at the country's southeast, with Amblyomma sculptum as its major contributor, followed by A. aureolatum and potentially Rhipicephalus sanguineus. Dogs have been considered sentinels, and in some areas the disease in dogs can precede human disease. Considering the importance of this disease for human health, the serological evidence in dogs, and the transmission of ticks between dogs and their owners, this review aimed to elucidate the importance of the epidemiological investigation, the diagnosis in dogs, and the role of veterinarians in Public Health to control vector-borne zoonotic diseases. We encourage veterinarians to include this rickettsial infection in the diagnosis of febrile diseases of common occurrence in dogs.
\end{abstract}

\section{Introduction}

Vector-borne diseases are globally important to human and animal health, since pathogens, vectors, and animal hosts reveal interactions through pathologies and their epidemiology, which differ among geographic zones, and may change over time [1]. Ticks and wildlife are among the main reservoirs of pathogens transmitted by arthropods of veterinary importance [2].

Human beings are causing important changes in the ecosystem, such as habitat fragmentation, global warming, and exploitation of natural resources, which have allowed interaction between man and pathogens potentially transmitted by arthropods $[3,4]$. The global Strategic Framework for health has been created to decrease the risk and minimize the impact of emerging infectious diseases at the animal-humanecosystem and socioeconomic interface [3]. Shaffer [5] suggested the use of surveillance policies for animals as part of an approach in One Health Perspective, in order to contribute to more coordinated actions towards human health.
It is against this background that stands out a holistic approach for the sake of Public Health, applying the concept of One Health, which recognizes that human welfare is linked to animals and the environment and so it seeks a combined action between physicians, ecologists, and veterinarians in the control of threats to Public Health.

Rickettsia rickettsii is the major bacterium responsible for the Brazilian Spotted Fever (BSF), a highly fatal disease with challenging diagnosis due to its nonspecific signs $[6,7]$. To assist the epidemiological surveillance, studies have been searching for sentinel animals, such as horses and dogs, with positive serological reaction in endemic areas $[8,9]$.

Based on the importance of BSF to human health, the evidence of clinical illness in dogs from areas with laboratoryconfirmed BSF in humans, and the potential transmission of ticks between dogs and their owners, this review aimed to discuss the importance of epidemiological surveys and laboratory diagnosis of BSF in dogs for Public Health, inspired by the principles of One World, One Health, a Strategic Framework that has been raised jointly by specialized agencies, such 
as World Health Organization (WHO), United Nations (UN) Food and Agriculture Organization (FAO), International Organization for Animal Health (OIE), and UN Children's Fund (UNICEF).

\section{The One Health Idea}

The idea that humans, animals, and the ecosystems are closely related has been under discussion since the late nineteenth century, when the first movements to integrate activities and research in human and animal health were raised $[3,10]$.

It is believed that emerging infectious diseases are related to socioeconomic conditions and ecological features, which allow identifying potential hotspots of injuries of animal origin, particularly at low latitudes, at areas where the notifications are substantially weak [11], a pattern that fits the epidemiological situation of BSF.

The Strategic Framework establishes a more interdisciplinary approach with international cooperation, in order to ensure health for humans, animals, and ecosystems [3, 10, 12]. However, people are reservoir of only a small number of zoonotic pathogens, so it is understood that an effective monitoring system requires the integration of physicians, who can identify human outbreaks, and veterinarians, that can identify animal reservoirs and sentinels [5, 13].

Veterinarians can contribute to the promotion of health through their knowledge on environmental conservation, the use of domestic animals as sentinels for the circulation of pathogens in the domestic and/or wildlife arenas, and occupational risk (due to the exposure to ticks) [12, 14, 15]. A study with veterinary students revealed that animal treatment with acaricides, avoiding contact with ticks, keeping vegetation cut down, and inspecting the body every three hours for the presence of ticks were the main prevention methods cited in control of BSF [15].

We believe that interdisciplinary participation in epidemiological investigation research and dissemination of articles and reports to scientific and health care assistance communities could be a mechanism to integrate information and improve strategies to control this disease.

\section{Brazilian Spotted Fever}

3.1. History. A disease caused by Rickettsia rickettsii was first described in the USA, and since then it has been confirmed in several countries, including Canada, Mexico, Panama, Costa Rica, Colombia, Brazil, Argentina, and possibly Guatemala [16-21]. In Brazil, this disease has been called Brazilian Spotted Fever (BSF) and it was first discovered in the state of São Paulo in 1928, where it was originally treated as "Exanthematic Typhus" [22]. The return of BSF reports in the 80s has shown that the disease has never ceased to occur; however it became detected as an acute disease affecting people from the same household or labor, albeit isolated cases have been described $[23,24]$. Since 2001, BSF is a nationally notifiable disease, considered endemic in southeastern Brazil [23, 25].

According to the Center of Disease Control, the gold standard serologic test for diagnosis of the disease is the indirect immunofluorescence assay (IFA) with $R$. rickettsii antigen, performed on two paired serum samples to demonstrate a significant (fourfold) rise in IgG antibody titers, since molecular diagnosis is not always routinely available to confirm cases (http://www.cdc.gov/rmsf/symptoms). In Brazil, 1141 human cases confirmed by IFA were notified between 2007 and 2015 , being $61.26 \%(699 / 1141)$ in the southeast, especially in the states of São Paulo (43.21\%, 493/1141), Minas Gerais $(8.15 \%, 93 / 1141)$, and Rio de Janeiro $(7.19 \%, 82 / 1141)$. The state of Santa Catarina is highlighted with $23.05 \%$ of human cases (263/1141). Amapá, Rondônia, and Amazonas contributed with a single confirmed human case each, in 2007, 2008, and 2011 (http://www.saude.gov.br/sinan).

3.2. Vectors, Reservoir, and Amplifying Hosts. Due to their capability to transmit a variety of zoonotic pathogens, ticks stand out on the concept of One Health. Brazil contains many biomes, rich and abundant fauna, and several species of arthropods, such as ticks of the Amblyomma genus, widely distributed in the Neotropical region [21].

Based on recent reassessment of the taxonomic and morphological status of Amblyomma cajennense (Fabricius, 1787), currently, the name A. cajennense sensu lato (s.l.) refers to a group of six species. According to geographical distributions, and host associations, A. cajennense sensu stricto (s.s.) applies to the tick found in the Amazonian region of South America, while A. sculptum applies to the tick found in the coastal states, and degraded areas of the Atlantic Forest, including all states in the southeast [26, 27].

Interestingly, the low host specificity of A. cajennense s.l. allows for their detection in many mammals including cattle, deer, and wild and domestic canids, besides man [7, 28, 29]. Amblyomma cajennense s.l. is implicated as the major species responsible for BSF, followed by A. aureolatum [29, 30]. In addition, the potential disease-transmission role of Rhipicephalus sanguineus is also increasingly studied [9, 31-35].

In the tick, transstadial and transovarian systems maintain the bacteria, which are transmitted to the vertebrate host during blood feeding, making arthropods simultaneously vector and reservoir [36-39]. However, infection rates by $R$. rickettsii in ticks under natural conditions tend to be low $(<1 \%)$, evidencing that $R$. rickettsii is pathogenic to ticks, and reinforcing the need of an amplifying host to ensure the maintenance of bacteria, such as capybaras, especially in endemic areas of São Paulo [40-44].

3.3. Amblyomma sculptum. In southeastern Brazil, the area with the highest concentration of BSF reports, the ecological setting in which the disease occurs is well described, including a voluminous population of Amblyomma ticks [21]. Horses and capybaras are among the most important primary hosts for all parasitic stages of A. cajennense s.l. [38, 45]. The capybara population has greatly increased in the state of São Paulo, and at this point it raises suspicions of its relationship to the emergence of BSF [44].

Although massive infestations with adult ticks occur in horses and capybaras in southeastern Brazil, nymphs of $A$. cajennense s.l. have shown better competence as vectors of 
R. rickettsii experimentally $[46,47]$, which is important, since these stages have less requirements regarding their hosts including dogs and people [28, 29]. In fact, most human cases of BSF seem to occur during the nymphs season of $A$. cajennense s.l., from July to November, possibly related to the aggressive behavior of nymphs, their effective spreading through the environment, and their small size, making their removal quite difficult [48].

3.4. Amblyomma aureolatum. Amblyomma aureolatum is yet another vector involved in BSF, with its ecological peculiarities. The "yellow dog tick" is found mainly in subtropical areas, with high humidity and mild temperatures throughout the year [49]. The population of A. aureolatum tends to be low and in southeastern Brazil, its distribution is restricted to Atlantic Forest, typically occurring in dogs with free access to rainforest [30, 49].

There are few reports of adults of $A$. aureolatum biting humans $[50,51]$. Thus, human cases transmitted by $A$. aureolatum seem to occur when dogs get infected by adults of this tick during incursions into the rainforest and go on to carry A. aureolatum to their households [21]. However, experimentally, this tick was more susceptible to $R$. rickettsii infection and more efficient to maintain the pathogen by transstadial and transovarian transmission than A. sculptum [52]. Another study with experimental infection of $A$. aureolatum demonstrated that $R$. rickettsii was preserved between transstadial and transovarial stages in $100 \%$ of the A. aureolatum ticks for several consecutive generations, and larvae, nymphs, and adults transmitted $R$. rickettsii to susceptible guinea pigs [53]. Recently it was suggested that the adult $A$. aureolatum needs only approximately 10 minutes attached to the body of a vertebrate host to transmit $R$. rickettsii [35].

Note that in some areas of southeastern Brazil, particularly in areas of the state of São Paulo, A. aureolatum can replace $A$. sculptum as the main vector of $R$. rickettsii to humans, being even more effective in transmitting the pathogen $[30,31,53]$.

3.5. Amblyomma ovale. In the past years, A. ovale has been implicated as a possible vector of new rickettsiosis in Brazil, since a human case of febrile disease with eschar (tache noire) was observed after tick biting in an Atlantic (ATL) Rainforest region of the state of São Paulo. Phylogenetic analysis revealed a new human rickettsiosis of the Spotted Fever Group (SFG), named ATL Rainforest Rickettsiosis, distinct from that caused by $R$. rickettsia [54]. Due to its phylogenetic similarity to $R$. parkeri, this new strain was called $R$. parkeri strain ATL Rainforest, which has been detected naturally infecting $A$. ovale ticks $[55,56]$. So far $A$. triste was the vector associated with infection by $R$. parkeri in South America, including Brazil $[57,58]$.

Experimentally, $100 \%$ of transstadial and transovarian transmission of $R$. parkeri to A. ovale was confirmed by PCR. Larvae and nymphs demonstrated high competence in transmission of the bacteria because all animals infested by these ticks' stages presented seroconversion when tested by IFA using $R$. parkeri antigens, but only half of the animals presented seroconversion after being infested by infected-adult ticks. Reproductive parameters of infected $A$. ovale females were low when compared to uninfected females, indicating deleterious effect of $R$. parkeri on this tick [56].

Amplifier hosts and reservoir in the ATL Rainforest Rickettsiosis have not been determined so far, but small rodents were shown to be important for $A$. ovale immature stages and high seroconversion prevalence [59]. Krawczak [56] suggested that $A$. ovale is an important vector on the epidemiology of $R$. parkeri strain ATL Rainforest, since this tick is often found in the ATL Rainforest ecosystem. Moreover, human bites by adult $A$. ovale tick are common [50]. Thus, humans can become infected if bitten by ticks detached from the dogs, suggesting the importance of dogs from the forests of endemic areas, mainly infested with $A$. ovale ticks $[21,59]$.

Serology studies have reported that dogs seroconvert, attaining very high titers against $R$. parkeri antigens $[55,59$, 60]. Furthermore, Medeiros et al. [60] reported identical sequences to $R$. parkeri strain ATL Rainforest in dogs coinfested with $A$. ovale ticks. So far, it can be supposed that some febrile human cases diagnosed as mild BSF were in fact ATL Rainforest Rickettsiosis [59].

3.6. Rhipicephalus sanguineus. The "brown dog tick" is possibly the tick with greater distribution, inhabiting urban and rural environments where dogs and humans live [18]. It is a three-host tick that feeds primarily on dogs and occasionally on other hosts [61]. Participation of Rh. sanguineus in the transmission of BSF is still a source of speculation, although this tick is already an important vector and reservoir of $R$. conorii responsible for the Mediterranean Spotted Fever in Europe, Africa, and Asia [21].

In Brazil, human parasitism by $R h$. sanguineus has been reported [61] but is still considered a rare event, particularly considering the close proximity of these ticks with man [51, 61]. Natural infection of $R h$. sanguineus by $R$. rickettsii in Brazil has been observed in endemic areas for BSF [30, 33, 62]. And even if the transmission to humans has not been proven yet, there is a favorable outlook in urban areas where $R h$. sanguineus is often found in pet or stray dogs [21]. Furthermore, these dogs can often move between urban and rural farming areas, being parasitized by ticks from both environments [30].

It is noteworthy that $R h$. sanguineus tends to be less aggressive to man, making the transmission occasional, particularly for those dealing with dogs most of the time [21].

The traditional mechanism by which the tick gets infected by $R$. rickettsia is during blood feeding of the vertebrate host or by transstadial and transovarian transmission [36, 37]. However, under natural conditions, low infection rates among tick populations suggest that these mechanisms are not enough to maintain the pathogen in the ecosystem [40, 41]. It is important to consider that $R$. rickettsii is pathogenic to the tick, causing decreased fertility and death [41]. Cofeeding transmission of $R$. rickettsii is not fully elucidated but may have an important role in the transmission of bacteria among ticks that feed in close proximity at the same host [39].

Considering that dogs can become infected by A. aureolatum during incursions into the rainforest and that bacteriainfected $A$. aureolatum can remain on the dog for several 
weeks, it is possible that tick-infested dogs carry infected ticks back to human households. The ticks may then drop off from the dog, contaminate the household environment, and accidentally bite humans. In a different scenario, $R h$. sanguineus ticks can become infected by cofeeding on the same dog with infected A. aureolatum ticks [21, 49, 59].

\section{Rickettsia rickettsii Infection in Dogs and the Role of Sentinels in Brazil}

Clinical disease caused by $R$. rickettsii in dogs is not easy to diagnose and has not been well described in South America, with few cases reported in the state of São Paulo, Brazil [7, 63].

Experimentally, dogs developed clinical illness characterized by fever, lethargy, anorexia, bilateral ocular discharge, scleral congestion, conjunctival edema, thrombocytopenia, and anemia [64]. Rickettsia rickettsii-reactive antibodies were shown in serum samples, and rickettsial DNA was detectable in blood 3 to 13 days after infection, indicating that a Brazilian strain of $R$. rickettsii is pathogenic for dogs [64].

Dogs, which remain close to both humans and naturally infected areas, can play a role as sentinels in an epidemiological approach $[34,65]$. The use of serological methods for the detection of anti-Rickettsia spp. antibodies in dogs has been reported in several Brazilian states, especially in the southeast $[9,32,34,62,66]$.

According to Cunha et al. [34], the dog's habit of entering rainforest regions and living in rural environments indicated a risk factor to the presence of anti-SFG rickettsiae antibodies.

Although SFG species share antigens that might cause group reactive serological responses, IFA is a highly sensitive and specific technique, used as the method of choice in serosurvey and screening tests in Brazil $[67,68]$. In addition, if serology to several SFG antigens demonstrates titers to one antigen at least fourfold higher than the others, we can assume which pathogen stimulated the immune response [9]. High titers to $R$. rickettsii in endemic areas for BSF, up to 1: 4096, or more, reinforce this hypothesis [34].

Clinical signs in dogs and humans may be similar, in such a way that the disease in dogs can precede the disease in humans, reinforcing the role of dogs as sentinels of BSF, a hypothesis that becomes stronger in USA, where cases of $R$. rickettsii in dogs and their owners have been found $[8,69,70]$.

In Brazil, canine monocytic ehrlichiosis (CME), caused by Ehrlichia canis, is the most common tick-transmitted canine disease [71]. As many clinical and laboratorial findings described in CME, fever, depression, petechial hemorrhage, and thrombocytopenia, are also described in dogs infected by R. rickettsii [72], and given that doxycycline is the treatment of choice for both diseases, it is possible that rickettsial infection in dogs is being misdiagnosed as CME [7, 9, 72].

Differential diagnosis is a great challenge, because dogs may present with subclinical infections or nonspecific clinical signs, often misdiagnosed as other diseases transmitted by arthropods like CME, Lyme's disease, babesiosis, leishmaniasis, anaplasmosis, and any febrile disease of unspecified etiology [73].

According to Labruna et al. [7], definitive diagnosis of naturally infected dogs is based on (1) serological analysis of paired samples; (2) anti-R. rickettsii titers fourfold higher than other spotted-fever group antigens occurring in Brazil; (3) rickettsial DNA detection in blood; (4) both clinical and laboratorial findings compatible with the disease; (5) doxycycline responsive treatment; and (6) epidemiological history with tick infestation and exposure to endemic areas.

Besides the dog, authors have attempted to elucidate the role of other domestic animals as sentinels of the BSF. Horses, considered primary hosts of A. cajennense s.l., are also an important object of study in the epidemiology of the disease.

Participation of horses as sentinels of infections caused by SFG has also been reported. One study suggested the ecological importance of cart horses as sentinels for BSF, since these horses are extensively used for transporting humans and heavy loads in urban and rural areas, being heavily infested with ticks [74]. Vianna et al. [75] believed that horses could be better sentinels to $R$. rickettsii than dogs, due to the presence of antibodies anti- $R$. rickettsii in $100 \%$ of the equine sera tested by IFA. However, Cunha et al. [34] after serosurvey in human foci of BSF observed that if the vector is not $A$. sculptum, horses present low serological reaction rate, which rules out these animals as good sentinels, while dogs can perform the role of sentinel for different vectors, since they can be parasitized by A. sculptum, A. aureolatum, A. ovale, and $R h$. sanguineus. This was reinforced by other studies in the state of São Paulo, which observed a higher frequency of horses with positive serology in areas with strong evidence that the main vector was A. cajennense s.l. [66].

\section{Conclusion and Perspectives}

Ticks of domestic animals may be involved in the epidemiology of several vector-borne diseases, which also affect humans. Even though the dogs are not the main host for R. rickettsii, they may carry infected ticks into the human dwellings. One of the most effective ways to assess the evidence of SFG pathogens circulation in sentinel animals is through serological tests, among which the IFA has been widely employed in dogs, particularly because of the easy access to samples, their intimate relationship with man, and parasitism by the same ticks.

Due to this challenging outlook it is possible that BSF in dogs is underestimated, since the nonspecific clinical signs may get confused with EMC, which is the most prevalent tickborne disease in dogs. As doxycycline is an effective treatment for patients with BSF or EMC, it is possible that dogs with acute febrile illness are not being routinely molecularly tested for BSF, since its cost is a limiting factor. Veterinarians should include rickettsial infections in the differential diagnosis of CME and other febrile diseases of nonspecific signs transmitted by common ticks, facilitating monitoring of BSF, since it is an important zoonosis with human fatalities when the diagnosis is delayed and treatment cannot be implemented in time.

Serology of these dogs could indicate prior exposure to rickettsial agents by the presence of IgG antibodies even before the reporting of human cases of BSF, warning about circulation of the bacteria, which added to the knowledge of the presence of ticks could help to improve BSF monitoring. 
When physicians, veterinarians, and other health professionals face every challenge the same way, they will understand that the traditional mechanisms for the study of diseases are full of unresolved gaps that can be addressed with interdisciplinary actions.

\section{Conflict of Interests}

The authors declare that there is no conflict of interests regarding the publication of this paper.

\section{Acknowledgments}

The authors are thankful to CNPq, Capes, and Faperj for the financial support.

\section{References}

[1] S. Harrus and G. Baneth, "Drivers for the emergence and reemergence of vector-borne protozoal and bacterial diseases," International Journal for Parasitology, vol. 35, no. 11-12, pp. 13091318, 2005.

[2] D. D. Colwell, F. Dantas-Torres, and D. Otranto, "Vector-borne parasitic zoonoses: emerging scenarios and new perspectives," Veterinary Parasitology, vol. 182, no. 1, pp. 14-21, 2011.

[3] World Organisation for Animal Health (OIE), Contributing to One World, One Health. A Strategic Framework for Reducing Risks of Infectious Diseases at the Animal-Human-Ecosystems Interface, World Organisation for Animal Health (OIE), Paris, France, 2008.

[4] A. K. Silveira and A. H. Fonseca, Caracterização de Ambientes com Potencial para Ocorrência de Carrapatos Transmissores de Agentes Patogênicos para Humanos, vol. 13 of Boletim do Parque Nacional Do Itatiaia, Ministério do Meio Ambiente, Instituto Chico Mendes de Conservação da Biodiversidade, ICMBio, 2011.

[5] L. E. Shaffer, "Role of surveillance in disease prevention and control: crossspecies surveillance contribution to one medicine," in Proceedings of the 145th AVMA Annual Convention, Schaumburg, Ill, USA, July 2008.

[6] D. H. Walker, "Rickettsia rickettsii: as virulent as ever," The American Journal of Tropical Medicine and Hygiene, vol. 66, no. 5, pp. 448-449, 2002.

[7] M. B. Labruna, O. Kamakura, J. Moraes-Filho, M. C. Horta, and R. C. Pacheco, "Rocky mountain spotted fever in dogs, Brazil," Emerging Infectious Diseases, vol. 15, no. 3, pp. 458-460, 2009.

[8] C. D. Paddock, O. Brenner, C. Vaid et al., "Short report: concurrent Rocky Mountain spotted fever in a dog and its owner," The American Journal of Tropical Medicine and Hygiene, vol. 66, no. 2, pp. 197-199, 2002.

[9] A. Pinter, M. C. Horta, R. C. Pacheco, J. Moraes-Filho, and M. B. Labruna, "Serosurvey of Rickettsia spp. in dogs and humans from an endemic area for Brazilian spotted fever in the State of São Paulo, Brazil," Cadernos de Saúde Pública, vol. 24, no. 2, pp. 247-252, 2008.

[10] P. D. Van Helden, L. S. Van Helden, and E. G. Hoal, "One world, one health: humans, animals and the environment are inextricably linked - a fact that needs to be remembered and exploited in our modern approach to health," EMBO Reports, vol. 14, no. 6, pp. 497-501, 2013.
[11] K. E. Jones, N. G. Patel, M. A. Levy et al., "Global trends in emerging infectious diseases," Nature, vol. 451, no. 7181, pp. 990993, 2008.

[12] D. Frank, “One world, one health, one medicine," Canadian Veterinary Journal, vol. 49, no. 11, pp. 1063-1065, 2008.

[13] J. Childs, R. E. Shope, D. Fish et al., "Emerging zoonoses," Emerging Infectious Diseases, vol. 4, no. 3, pp. 453-454, 1998.

[14] D. A. Jessup, M. A. Miller, C. Kreuder-Johnson et al., "Sea otters in a dirty ocean," Journal of the American Veterinary Medical Association, vol. 231, no. 11, pp. 1648-1652, 2007.

[15] P. M. R. Barros-Silva, L. X. Fonseca, M. E. Carneiro, K. M. A. Vilges, S. V. Oliveira, and R. Gurgel-Gonçalves, "Occupational risk of spotted fever: an evaluation of knowledge, attitudes and prevention practices among veterinary medicine students," Revista de Patologia Tropical, vol. 43, no. 4, pp. 389-397, 2014.

[16] A. S. Chapman, S. M. Murphy, L. J. Demma et al., "Rocky Mountain spotted fever in the United States, 1997-2002," VectorBorne and Zoonotic Diseases, vol. 6, no. 2, pp. 170-178, 2006.

[17] D. Estripeaut, M. G. Aramburú, X. Sáez-Llorens et al., "Rocky Mountain spotted fever, Panama," Emerging Infectious Diseases, vol. 13, no. 11, pp. 1763-1765, 2007.

[18] D. Raoult and P. Parola, Rickettsial Diseases (Infectious Disease and Therapy), CRC Press, New York, NY, USA, 2007.

[19] L. Hun, X. Cortés, and L. Taylor, "Molecular characterization of Rickettsia rickettsii isolated from human clinical samples and from the rabbit tick Haemaphysalis leporispalustris collected at different geographic zones in Costa Rica," American Journal of Tropical Medicine and Hygiene, vol. 79, no. 6, pp. 899-902, 2008.

[20] M. E. Eremeeva, E. Berganza, G. Suarez et al., "Investigation of an outbreak of rickettsial febrile illness in Guatemala, 2007," International Journal of Infectious Diseases, vol. 17, no. 5, pp. e304-e311, 2013.

[21] M. P. J. Szabó, A. Pinter, and M. B. Labruna, "Ecology, biology and distribution of spotted-fever tick vectors in Brazil," Frontiers in Cellular and Infection Microbiology, vol. 3, no. 27, pp. 1-9, 2013.

[22] E. Dias and A. V. Martins, "Spotted fever in Brazil," American Journal of Tropical Medicine, no. 19, pp. 103-108, 1939.

[23] E. R. S. De Lemos, F. B. F. Alvarenga, M. L. Cintra et al., "Spotted fever in Brazil: a seroepidemiological study and description of clinical cases in an endemic area in the state of São Paulo," The American Journal of Tropical Medicine and Hygiene, vol. 65, no. 4, pp. 329-334, 2001.

[24] M. A. M. Galvão, "Diagnósticos e inquéritos sorológicos para riquetsioses do gênero rickettsia no Brasil," Revista Brasileira de Parasitologia Veterinária, vol. 13, no. 1, pp. 188-189, 2004.

[25] J. Brites-Neto, F. A. Nieri-Bastos, J. Brasil et al., "Environmental infestation and rickettsial infection in ticks in an area endemic for Brazilian spotted fever," Revista Brasileira de Parasitologia Veterinaria, vol. 22, no. 3, pp. 367-372, 2013.

[26] T. F. Martins, A. R. M. Barbieri, F. B. Costa et al., "Estudo do complexo Amblyomma cajennense (Acari: Ixodidae) no Brasil," BEPA, Boletim Epidemiológico Paulista, vol. 10, no. 117, pp. 8-13, 2013.

[27] S. Nava, L. Beati, M. B. Labruna, A. G. Cáceres, A. J. Mangold, and A. A. Guglielmone, "Reassessment of the taxonomic status of Amblyomma cajennense (Fabricius, 1787) with the description of three new species, Amblyomma tonelliae n. sp., Amblyomma interandinum n. sp. and Amblyomma patinoi n. sp., and reinstatement of Amblyomma mixtum Koch, 1844, and Amblyomma sculptum Berlese, 1888 (Ixodida: Ixodidae)," Ticks and Tick-Borne Diseases, vol. 5, no. 3, pp. 252-276, 2014. 
[28] M. B. Labruna, C. E. Kerber, F. Ferreira, J. L. Faccini, D. T. De Waal, and S. M. Gennari, "Risk factors to tick infestations and their occurrence on horses in the state of São Paulo, Brazil," Veterinary Parasitology, vol. 97, no. 1, pp. 1-14, 2001.

[29] M. B. Labruna, "Ecology of Rickettsia in South America," Annals of the New York Academy of Sciences, vol. 1166, pp. 156-166, 2009.

[30] M. Ogrzewalska, D. G. Saraiva, J. Moraes-Filho et al., "Epidemiology of Brazilian spotted fever in the Atlantic Forest, state of Sao Paulo, Brazil," Parasitology, vol. 139, no. 10, pp. 1283-1300, 2012.

[31] A. Pinter and M. B. Labruna, "Isolation of Rickettsia rickettsii and Rickettsia bellii in cell culture from the tick Amblyomma aureolatum in Brazil," Annals of the New York Academy of Sciences, vol. 1078, pp. 523-529, 2006.

[32] J. Moraes-Filho, A. Pinter, R. C. Pacheco et al., "New epidemiological data on Brazilian spotted fever in an endemic area of the state of São Paulo, Brazil," Vector-Borne and Zoonotic Diseases, vol. 9, no. 1, pp. 73-78, 2009.

[33] N. C. Cunha, A. H. Fonseca, J. Rezende et al., "First identification of natural infection of Rickettsia rickettsii in the Rhipicephalus sanguineus tick, in the State of Rio de Janeiro," Pesquisa Veterinaria Brasileira, vol. 29, no. 2, pp. 105-108, 2009.

[34] N. C. Cunha, E. R. S. Lemos, T. Rozental et al., "Rickettsiae of the Spotted Fever group in dogs, horses and ticks: an epidemiological study in an endemic region of the State of Rio de Janeiro, Brazil," Revista Brasileira de Medicina Veterinária, vol. 36, no. 3, pp. 294-300, 2014.

[35] D. G. Saraiva, H. S. Soares, J. F. Soares, and M. B. Labruna, "Feeding period required by Amblyomma aureolatum ticks for transmission of Rickettsia rickettsii to vertebrate hosts," Emerging Infectious Diseases, vol. 20, no. 9, pp. 1504-1510, 2014.

[36] D. Raoult and V. Roux, "Rickettsioses as paradigms of new or emerging infectious diseases," Clinical Microbiology Reviews, vol. 10, no. 4, pp. 694-719, 1997.

[37] M. A. M. Galvão, L. J. da Silva, E. M. Mendes Nascimento, S. B. Calic, R. de Sousa, and F. Bacellar, "Riquetsioses no Brasil e Portugal: ocorrência, distribuição e diagnóstico," Revista de Saude Publica, vol. 39, no. 5, pp. 850-856, 2005.

[38] E. Guedes, R. C. Leite, M. C. A. Prata, R. C. Pacheco, D. H. Walker, and M. B. Labruna, "Detection of Rickettsia rickettsii in the tick Amblyomma cajennense in a new Brazilian spotted fever-endemic area in the state of Minas Gerais," Memórias do Instituto Oswaldo Cruz, vol. 100, no. 8, pp. 841-845, 2005.

[39] P. Parola, C. D. Paddock, and D. Raoult, "Tick-borne rickettsioses around the world: emerging diseases challenging old concepts," Clinical Microbiology Reviews, vol. 18, no. 4, pp. 719756, 2005.

[40] J. E. McDade and V. F. Newhouse, "Natural history of Rickettsia rickettsii," Annual Review of Microbiology, vol. 40, pp. 287-309, 1986.

[41] M. L. Niebylski, M. G. Peacock, and T. G. Schwan, "Lethal effect of Rickettsia rickettsii on its tick vector (Dermacentor andersoni)," Applied and Environmental Microbiology, vol. 65, no. 2, pp. 773-778, 1999.

[42] M. B. Labruna, T. Whitworth, M. C. Horta et al., "Rickettsia species infecting Amblyomma cooperi ticks from an area in the state of São Paulo, Brazil, where Brazilian Spotted Fever is endemic," Journal of Clinical Microbiology, vol. 42, no. 1, pp. 9098, 2004.

[43] R. C. Pacheco, M. C. Horta, J. Moraes-Filho, A. C. Ataliba, A. Pinter, and M. B. Labruna, "Rickettsial infection in capybaras
(Hydrochoerus hydrochaeris) from São Paulo, Brazil: serological evidence for infection by Rickettsia bellii and Rickettsia parkeri," Biomédica, vol. 27, no. 3, pp. 364-371, 2007.

[44] C. E. Souza, J. Moraes-Filho, M. Ogrzewalska et al., "Experimental infection of capybaras Hydrochoerus hydrochaeris by Rickettsia rickettsii and evaluation of the transmission of the infection to ticks Amblyomma cajennense," Veterinary Parasitology, vol. 161, no. 1-2, pp. 116-121, 2009.

[45] A. M. L. Vieira, C. E. Souza, M. B. Labruna, R. C. Mayo, S. S. L. Souza, and V. L. F. Camargo-Neves, Manual de Vigilância Acarológica, Estado de São Paulo, Secretaria de Saúde, Estado da São Paulo, São Paulo, Brazil, 2004.

[46] D. M. Barros-Battesti, M. Arzua, and G. H. Bechara, Carrapatos de Importancia Médico-Veterinaria da Regiao Neotropical: Um Guia Ilustrado Para Identificação de Espécies, Vox/ICTTD3/Butantan, São Paulo, Brazil, 2006.

[47] J. F. Soares, H. S. Soares, A. M. Barbieri, and M. B. Labruna, "Experimental infection of the tick Amblyomma cajennense, cayenne tick, with Rickettsia rickettsii, the agent of Rocky Mountain spotted fever," Medical and Veterinary Entomology, vol. 26, no. 2, pp. 139-151, 2012.

[48] A. Pinter, A. C. França, C. E. Souza et al., "Febre Maculosa Brasileira," BEPA Suplemento, vol. 8, no. 1, pp. 3-31, 2011.

[49] A. Pinter, R. A. Dias, S. M. Gennari, and M. B. Labruna, "Study of the seasonal dynamics, life cycle, and host specificity of Amblyomma aureolatum (Acari: Ixodidae)," Journal of Medical Entomology, vol. 41, no. 3, pp. 324-332, 2004.

[50] A. A. Guglielmone, L. Beati, D. M. Barros-Battesti et al., "Ticks (Ixodidae) on humans in South America," Experimental and Applied Acarology, vol. 40, no. 2, pp. 83-100, 2006.

[51] N. M. Serra-Freire, "Occurrence of ticks (Acari: Ixodidae) on human hosts, in three municipalities in the State of Pará, Brazil," Revista Brasileira de Parasitologia Veterinaria, vol. 19, no. 3, pp. 141-147, 2010.

[52] M. B. Labruna, M. Ogrzewalska, T. F. Martins, A. Pinter, and M. C. Horta, "Comparative susceptibility of larval stages of Amblyomma aureolatum, Amblyomma cajennense, and Rhipicephalus sanguineus to infection by Rickettsia rickettsii," Journal of Medical Entomology, vol. 45, no. 6, pp. 1156-1159, 2008.

[53] M. B. Labruna, M. Ogrzewalska, J. F. Soares et al., "Experimental infection of Amblyomma aureolatum ticks with Rickettsia rickettsii," Emerging Infectious Diseases, vol. 17, no. 5, pp. 829-834, 2011.

[54] M. G. Spolidorio, M. B. Labruna, E. Mantovani, P. E. Brandão, L. J. Richtzenhain, and N. H. Yoshinari, "Novel spotted fever group rickettsiosis, Brazil," Emerging Infectious Diseases, vol. 16, no. 3, pp. 521-523, 2010.

[55] G. S. Sabatini, A. Pinter, F. A. Nieri-Bastos, A. Marcili, and M. B. Labruna, "Survey of ticks (Acari: Ixodidae) and their rickettsia in an Atlantic rain forest reserve in the state of São Paulo, Brazil," Journal of Medical Entomology, vol. 47, no. 5, pp. 913-916, 2010.

[56] F. S. Krawczak, Avaliação da dinâmica da infecção por Rickettsia parkeri cepa Mata Atlântica, agente etiológico de uma nova riquetsiose brasileira, em carrapatos Amblyomma ovale Koch, 1844 naturalmente infectados [M.S. dissertation], Universidade de São Paulo, São Paulo, Brazil, 2012, http://www.teses.usp.br/ teses/disponiveis/10/10134/tde-11062013-155536/pt-br.php.

[57] Y. Romer, A. C. Seijo, F. Crudo et al., "Rickettsia parkeri rickettsiosis, Argentina," Emerging Infectious Diseases, vol. 17, no. 7, pp. 1169-1173, 2011. 
[58] I. Silveira, R. C. Pacheco, M. P. J. Szabó, H. G. C. Ramos, and M. B. Labruna, "Rickettsia parkeri in Brazil," Emerging Infectious Diseases, vol. 13, no. 7, pp. 1111-1113, 2007.

[59] M. P. J. Szabó, F. A. Nieri-Bastos, M. G. Spolidorio, T. F. Martins, A. M. Barbieri, and M. B. Labruna, "In vitro isolation from Amblyomma ovale (Acari: Ixodidae) and ecological aspects of the Atlantic rainforest Rickettsia, the causative agent of a novel spotted fever rickettsiosis in Brazil," Parasitology, vol. 140, no. 6, pp. 719-728, 2013.

[60] A. P. Medeiros, A. P. de Souza, A. B. de Moura et al., "Spotted fever group Rickettsia infecting ticks (Acari: Ixodidae) in the state of Santa Catarina, Brazil," Memórias do Instituto Oswaldo Cruz, vol. 106, no. 8, pp. 926-930, 2011.

[61] F. Dantas-Torres, L. A. Figueredo, and S. P. Brandão-Filho, "Rhipicephalus sanguineus (Acari: Ixodidae), o carrapato vermelho do cão, parasitando humanos no Brasil," Revista da Sociedade Brasileira de Medicina Tropical, vol. 39, pp. 64-67, 2006.

[62] R. C. Pacheco, J. Moraes-Filho, E. Guedes et al., "Rickettsial infections of dogs, horses and ticks in Juiz de Fora, southeastern Brazil, and isolation of Rickettsia rickettsii from Rhipicephalus sanguineus ticks," Medical and Veterinary Entomology, vol. 25, no. 2, pp. 148-155, 2011.

[63] P. Parola, C. D. Paddock, C. Socolovschi et al., "Update on tickborne rickettsioses around the world: a geographic approach," Clinical Microbiology Reviews, vol. 26, no. 4, pp. 657-702, 2013.

[64] E. M. Piranda, J. L. H. Faccini, A. Pinter et al., "Experimental infection of dogs with a Brazilian strain of Rickettsia rickettsii: clinical and laboratory findings," Memorias do Instituto Oswaldo Cruz, vol. 103, no. 7, pp. 696-701, 2008.

[65] L. D. Cardoso, R. N. Freitas, C. L. Mafra et al., "Caracterização de Rickettsia spp. circulante em foco silencioso de febre maculosa brasileira no município de Caratinga, Minas Gerais, Brasil," Cadernos de Saúde Pública, vol. 22, no. 3, pp. 495-501, 2006.

[66] M. C. Horta, M. B. Labruna, A. Pinter, P. M. Linardi, and T. T. S. Schumaker, "Rickettsia infection in five areas of the state of São Paulo, Brazil," Memórias do Instituto Oswaldo Cruz, vol. 102, no. 7, pp. 793-801, 2007.

[67] V. M. F. Del Guercio, M. M. M. Rocha, H. H. B. Melles, V. C. L. Lima, and M. G. Pignatti, "Febre maculosa no município de Pedreira, SP, Brasil. Inquérito sorológico," Revista da Sociedade Brasileira de Medicina Tropical, vol. 30, no. 1, pp. 47-52, 1997.

[68] H. H. Melles, S. Colombo, and E. R. S. Lemos, "Isolamento de rickettsia em cultura de célula vero," Revista da Sociedade Brasileira de Medicina Tropical, vol. 32, no. 5, pp. 469-473, 1999.

[69] L. Kidd, B. Hegarty, D. Sexton, and E. Breitschwerdt, "Molecular characterization of Rickettsia rickettsii infecting dogs and people in North Carolina," Annals of the New York Academy of Sciences, vol. 1078, pp. 400-409, 2006.

[70] B. N. Elchos and J. Goddard, "Implications of presumptive fatal Rocky Mountain spotted fever in two dogs and their owner," Journal of the American Veterinary Medical Association, vol. 223, no. 10, pp. 1450-1452, 2003.

[71] D. M. Aguiar, G. T. Cavalcante, A. Pinter, S. M. Gennari, L. M. A. Camargo, and M. B. Labruna, "Prevalence of Ehrlichia canis (Rickettsiales: Anaplasmataceae) in dogs and Rhipicephalus sanguineus (Acari: Ixodidae) ticks from Brazil," Journal of Medical Entomology, vol. 44, no. 1, pp. 126-132, 2007.

[72] C. B. Grindem, E. B. Breitschwerdt, P. C. Perkins, L. D. Cullins, T. J. Thomas, and B. C. Hegarty, "Platelet-associated immunoglobulin (antiplatelet antibody) in canine rocky mountain spotted fever and ehrlichiosis," Journal of the American Animal Hospital Association, vol. 35, no. 1, pp. 56-61, 1999.
[73] F. Dantas-Torres, "Canine vector-borne diseases in Brazil," Parasites and Vectors, vol. 1, no. 1, article 25, 2008.

[74] B. S. Milagres, A. F. Padilha, R. M. Barcelos et al., "Rickettsia in synanthropic and domestic animals and their hosts from two areas of low endemicity for Brazilian spotted fever in the Eastern Region of Minas Gerais, Brazil," The American Journal of Tropical Medicine and Hygiene, vol. 83, no. 6, pp. 1305-1307, 2010.

[75] M. C. B. Vianna, M. C. Horta, L. A. Sangioni et al., "Rickettsial spotted fever in Capoeirão village, Itabira, Minas Gerais, Brazil," Revista do Instituto de Medicina Tropical de Sao Paulo, vol. 50, no. 5, pp. 297-301, 2008. 

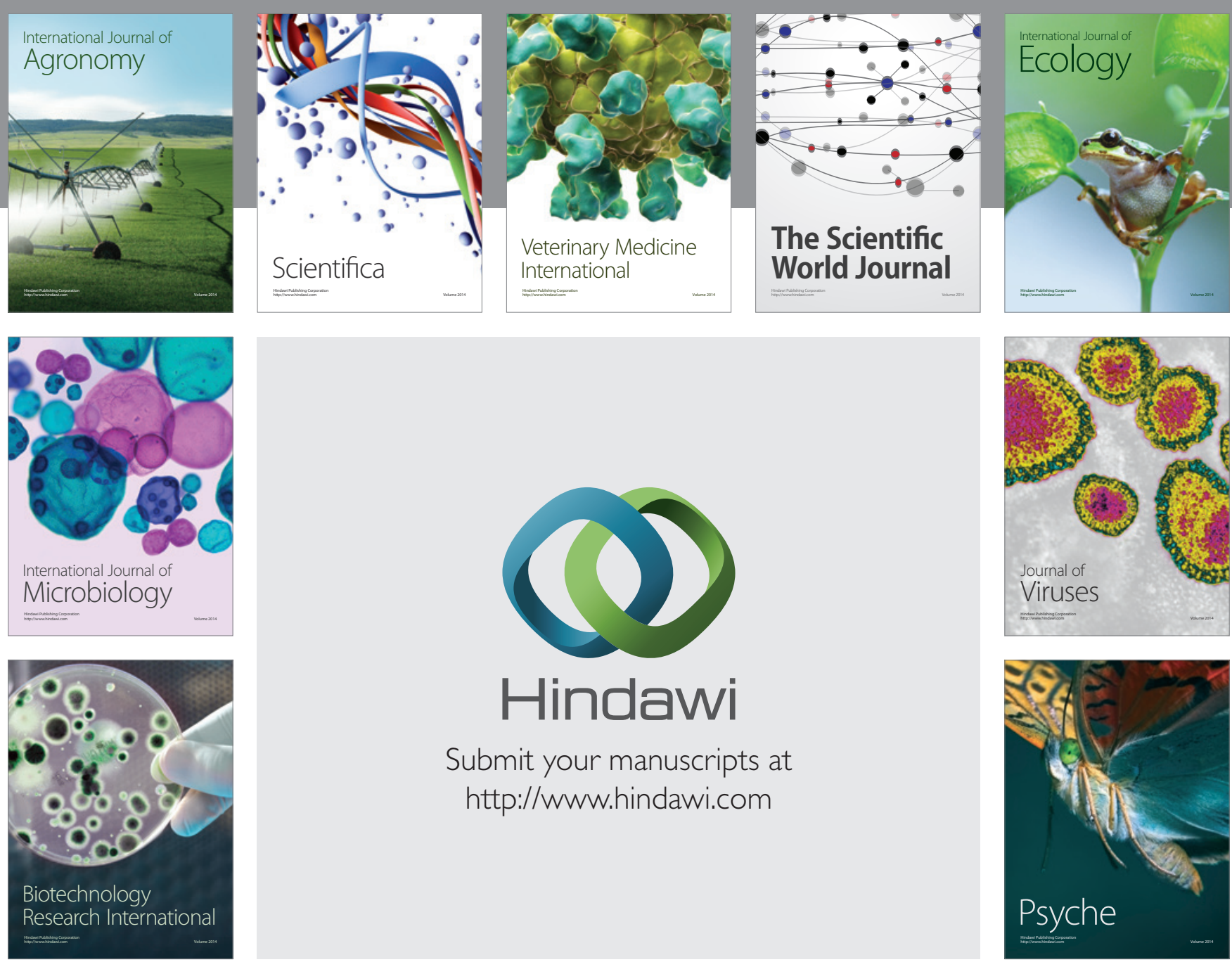

Submit your manuscripts at

http://www.hindawi.com
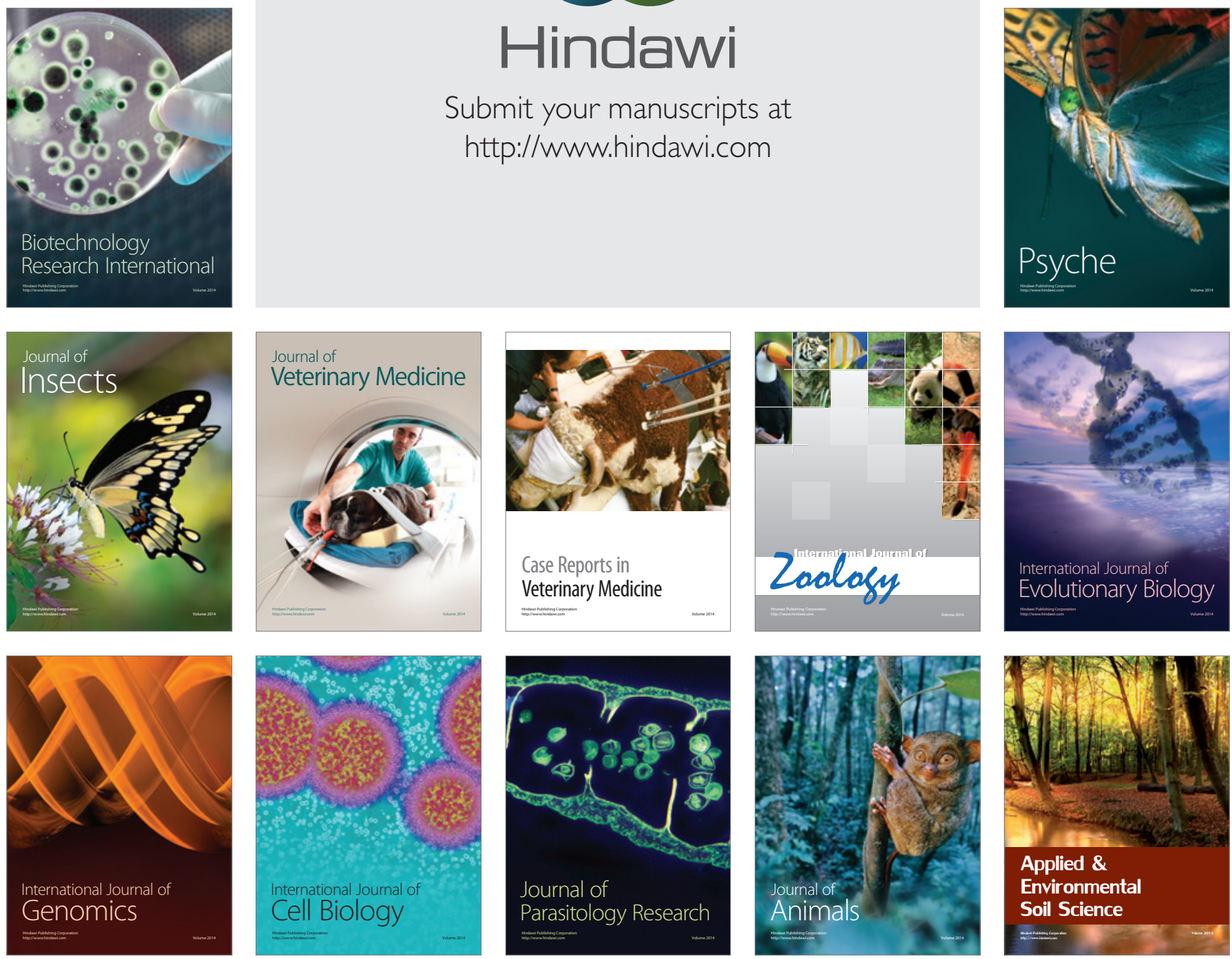